\title{
Correction: TROP2 promotes proliferation, migration and metastasis of gallbladder cancer cells by regulating PI3K/AKT pathway and inducing EMT
}

\section{Xinxing $\mathrm{Li}^{1, *}$, Shifeng Teng ${ }^{1, *}$, Yanyan Zhang ${ }^{1, *}$, Weigang Zhang ${ }^{1}$, Xianwen Zhang ${ }^{1}$, Kai Xu' ${ }^{1}$, Houshan Yao ${ }^{1}$, Jun Yao ${ }^{1}$, Haolu Wang ${ }^{2}$, Xiaowen Liang ${ }^{2}$ and Zhiqian Hu${ }^{1}$ \\ ${ }^{1}$ Department of General Surgery, Changzheng Hospital, The Second Military Medical University, Shanghai 200003, China \\ ${ }^{2}$ Therapeutics Research Centre, School of Medicine, The University of Queensland, Princess Alexandra Hospital, Woolloongabba QLD 4102, Australia}

*These authors have contributed equally to this work

\section{Published: November 05, 2019}

Copyright: Li et al. This is an open-access article distributed under the terms of the Creative Commons Attribution License 3.0 (CC BY 3.0 ), which permits unrestricted use, distribution, and reproduction in any medium, provided the original author and source are credited.

This article has been corrected: Due to errors in image processing, Figure $2 \mathrm{C}$ contains an image from the wrong cell line (GBC-SD cells). The corrected Figure 2C is shown below. The authors declare that these corrections do not change the results or conclusions of this paper.

Original article: Oncotarget. 2017; 8:47052-47063. https://doi.org/10.18632/oncotarget.16789

A

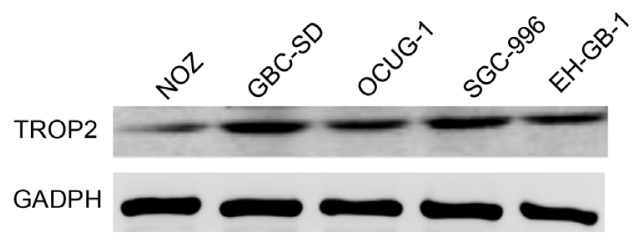

C

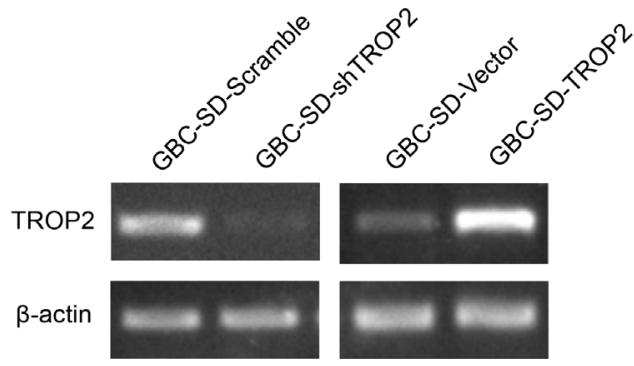

B
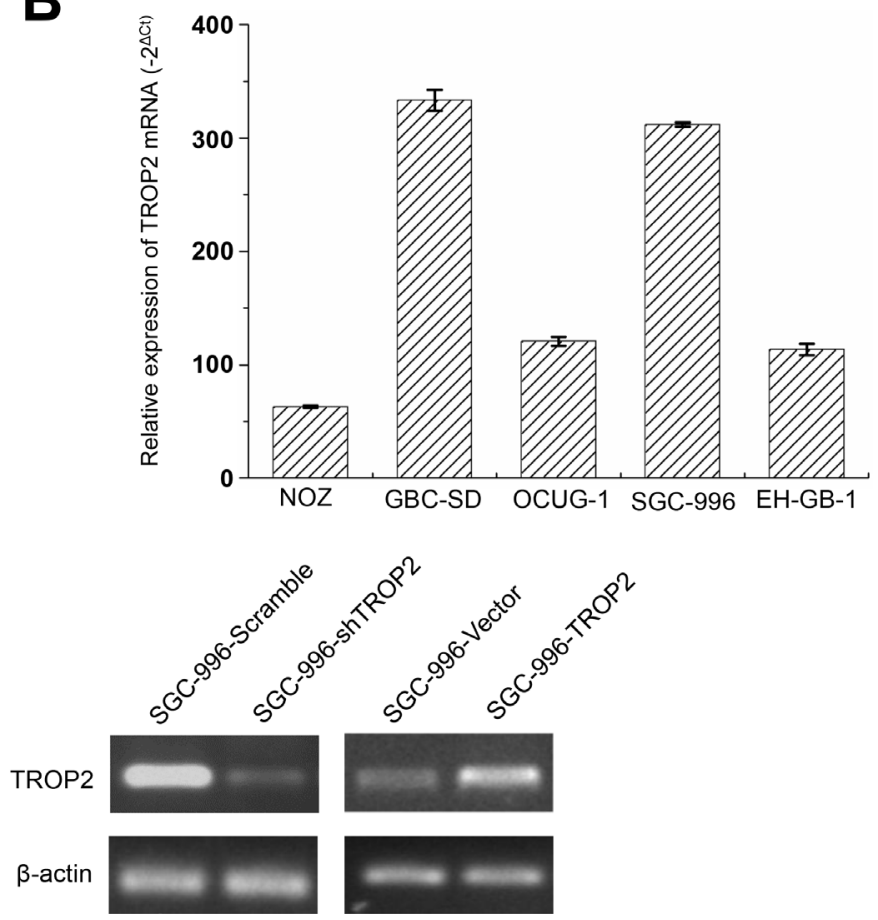

Figure 2: TROP2 expression in GBC cell lines. (A) The TROP2 protein expression of human GBC cell lines NOZ, GBC-SD, OCUG-1, SGC-996 and EH-GB-1B. (B) The TROP2 mRNA expression of human GBC cell lines NOZ, GBC-SD, OCUG-1, SGC-996 and EHGB-1B. (C) TROP2 mRNA expressions of GBC-SD and SGC-996 cells after RNA interference and plasmid transfection. Cells were transfected with scramble sh-RNA and empty vector as negative controls. Each experiment was repeated three times. 